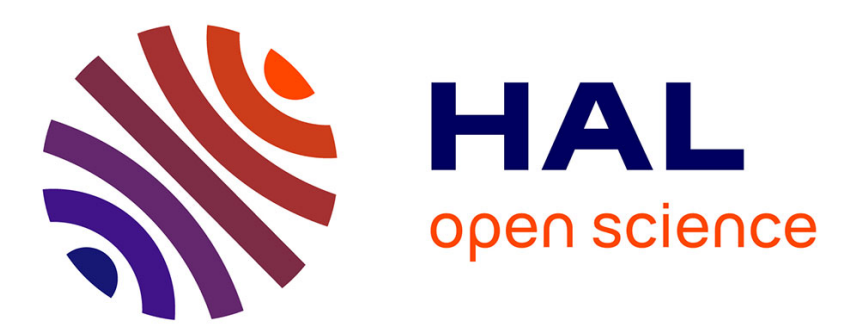

\title{
A multilayer innovative solution to improve the adhesion of nanocrystalline diamond coatings
}

\author{
Angeline Poulon-Quintin, Cyril Faure, Lionel Teulé-Gay, Jean Pierre Manaud
}

\section{To cite this version:}

Angeline Poulon-Quintin, Cyril Faure, Lionel Teulé-Gay, Jean Pierre Manaud. A multilayer innovative solution to improve the adhesion of nanocrystalline diamond coatings. Applied Surface Science, 2015, 331, pp.27-34. 10.1016/j.apsusc.2015.01.050 . hal-01113708

\section{HAL Id: hal-01113708 \\ https://hal.science/hal-01113708}

Submitted on 11 Feb 2015

HAL is a multi-disciplinary open access archive for the deposit and dissemination of scientific research documents, whether they are published or not. The documents may come from teaching and research institutions in France or abroad, or from public or private research centers.
L'archive ouverte pluridisciplinaire HAL, est destinée au dépôt et à la diffusion de documents scientifiques de niveau recherche, publiés ou non, émanant des établissements d'enseignement et de recherche français ou étrangers, des laboratoires publics ou privés. 


\title{
A multilayer innovative solution to improve the adhesion of nanocrystalline diamond coatings
}

Poulon-Quitin A., Faure C., Teulé-Gay Lionel, Manaud J.-P.

\begin{abstract}
Nano-crystalline diamond (NCD) films grown under negative biased substrates by chemical vapor deposition (CVD) are widely used as surface overlay coating onto cermet WC-Co cutting tools to get better performances. To improve the diamond adhesion to the cermet substrate, suitable multi-layer systems have been added. They are composed of a cobalt diffusion barrier close to the substrate (single and sequenced nitrides layers) coated with a nucleation extra layer to improve the nucleus density of diamond during CVD processing. For all systems, before and after diamond deposition, transmission electron microscopy (TEM) has been performed for a better understanding of the diffusion phenomena occurring at the interfaces and to evaluate the presence of graphitic species at the interface with the diamond. Innovative multilayer system dedicated to the regulation of cobalt diffusion coated with a bilayer system optimized for the carbon diffusion control, is shown as an efficient solution to significantly reduce the graphite layer formation at the interface with the diamond down to $10 \mathrm{~nm}$ thick and to increase the adhesion of NCD diamond layer as scratch-tests confirm.
\end{abstract}

\section{Introduction}

Advances in tooling require the use of cemented carbides with a reduced grain size to improve mechanical properties and abrasion resistance [1]. However, an increase of the substrate Co content is necessary ( $>10 \mathrm{wt} \%)$ to improve toughness deterioration and to extend the tool lifetime. When diamond films are deposited by chemical vapor deposition (CVD) onto WC-Co substrates containing more than $6 \mathrm{wt} \% \mathrm{Co}$, the performances of diamond/substrate interfaces are deteriorated due to the formation of $\mathrm{sp}^{2}$ graphitic species resulting from the Co binder catalytic properties [2], [3] and [4]. As a strong interfacial adhesion is required, a chemical bond between diamond and substrate is preferred to physical interactions such as mechanical bonding by grains overlapping.

To improve the interfacial adhesion and to limit the graphitization, an interlayer with a low diffusion coefficient for carbon [5] and cobalt can be used. Combined with an intermediate thermal expansion coefficient between WC-Co and diamond, the selected interlayer system might relax the residual thermal stresses. Refractory or transition metal nitrides like TaN and ZrN act as efficient Co diffusion barriers ( $1 \mu \mathrm{m}$ thick) for CVD diamond deposition on WC-Co substrates containing $12 \mathrm{wt} \%$ of cobalt [6] and [7]. Combined with a top molybdenum layer $(<0.5 \mu \mathrm{m})$ added to improve the diamond nucleation, the efficiency of two different bilayer systems ( $\mathrm{TaN}-\mathrm{Mo}$ and $\mathrm{ZrN}-\mathrm{Mo}$ ) has been already evidenced to reduce the Co diffusion and to improve diamond nucleation [7] and [8].

In the present paper, two new multilayer systems (based on TaN, ZrN and Mo) are studied. They are composed of both cobalt diffusion barrier and carbon diffusion control systems. This paper is focused on the consequences that defining the architecture of the diffusion layers entails on carbon and cobalt diffusion. The aim is to prevent the graphite formation at the interface with diamond top layer, and to improve adhesion of nano-crystalline diamond (NCD) layer. 


\section{Experimental}

WC-12\%wt Co cermet substrates (Plates $16 \mathrm{~mm} \times 16 \mathrm{~mm} \times 5 \mathrm{~mm}$ ) micrograin grade $(\sim 0.7 \mu \mathrm{m}$, ultrafine grade EMT612 from Extramet $\left.{ }^{(}\right)$were directly cleaned ultrasonically in acetone and rinsed using isopropanol vapor. Interlayers were deposited by a $1356 \mathrm{MHz}$ reactive magnetron sputtering plant (Plassys MP700 equipped with two $75 \mathrm{~mm}$ in diameter targets for sequenced deposits and an Anatech IS 3000 ion source) using Ta, Zr and Mo targets (disks of pure Ta (99.98\%), Zr (99.8\%) and Mo (99.98\%) from Cerac, Inc.) [9]. Deposition of interlayers was performed with additional heating of substrates at $673 \mathrm{~K}$. The cleaning procedure was completed by in situ high energy Ar ion beam (50 eV, $0.02 \mathrm{~Pa}, 10 \mathrm{~min}$ ). The deposition reactive environment was an argon/nitrogen atmosphere and the total pressure during the deposition process was $0.5 \mathrm{~Pa}$. Reactive sputtering parameters given in Table 1, have been optimized to obtain stoichiometric $\mathrm{MN}$ nitrides ( $\mathrm{M}=\mathrm{Ta}$ or $\mathrm{Zr}$ ) when $\mathrm{M}_{2} \mathrm{~N}$ compounds should be preferentially synthesized under low temperature and pressure conditions due to their lower Gibbs free energies of formation.

Two new different systems are selected for this study:

TaN-Mo bilayer system: To reduce TaN grain size and change the grain morphology from columnar (system named TFG (TaN fiber-grained bilayer system) [7] and [8]) to rounded grains, a sequenced process was used. Each sputtered TaN layer ( $100 \mathrm{~nm}$ thick) was post-etched by an ion beam (acceleration $-50 \mathrm{~V}$; anode $500 \mathrm{~V}$; ion dose $30 \mu \mathrm{A} / \mathrm{cm}^{2}$ ) using a reactive mixture of $\mathrm{Ar}-6$ vol\% $\mathrm{N}_{2}$ under a total pressure $0.02 \mathrm{~Pa}$ for $1 \mathrm{~h}$. The sputter/etching processes were repeated to finally obtain a TaN layer of $0.3 \mu \mathrm{m}$ thick. Reduction of grain size increases the grain boundary diffusion path length for species when layer thickness is kept constant. The thickness value was then selected to have a similar grain boundary diffusion path length for species when moving from columnar grains to nanograins. The aim was to keep the ability of TaN to prevent cobalt diffusion at grain boundaries. Mo nucleation top layer ( $0.5 \mu \mathrm{m}$ thick) is then deposited. This system is named TNG (TaN nano-grained bilayer system).

Multilayer system: multilayer coating composed of 9 periods of a $\operatorname{TaN}(50 \mathrm{~nm})$ and $\operatorname{ZrN}(30 \mathrm{~nm})$ bilayer system, is covered with a $\operatorname{TaN}(0.5 \mu \mathrm{m})-\mathrm{Mo}(0.5 \mu \mathrm{m}) \mathrm{TFG}$ bilayer system. Because, micro-grained TaN layer is completely carburized during the diamond deposition process and $\operatorname{ZrN}(1 \mu \mathrm{m})-\mathrm{Mo}(0.5 \mu \mathrm{m})$ bilayer system is more efficient than $\operatorname{TaN}(1 \mu \mathrm{m})-$ $\mathrm{Mo}(0.5 \mu \mathrm{m})$ to prevent Co diffusion from the substrate when a bias is used during the process [7], the use of a TaN-ZrN multilayer system was thought: (1) to prevent efficiently the diffusion of cobalt thanks to the changing of the $\mathrm{ZrN}$ and TaN layers and the multiplication of the interfaces, and (2) to regulate the diffusion of carbon in addition to the regulatory effect of our conventional top TaN-Mo bilayer system dedicated to control both carbon diffusion and diamond nucleation close to the interface with diamond. TaN and ZrN layer thicknesses in the multilayer system were selected to keep constant the final grain boundary diffusion path length compared to the previous system. This system is named TZT (TaN-ZrN multilayer coated with a TaN/Mo bilayer system).

Multilayer nano crystalline diamond coating was then deposited in a microwave enhanced plasma chemical vapor deposition reactor (silica tube crossing orthogonally the wave guide powered with a $2 \mathrm{~kW}, 2.45 \mathrm{~Hz}$ Raytech generator) using a hydrogen-methane mixture (total pressure $40 \mathrm{hPa}$ ). Multilayer diamond coatings are synthesized without prior seeding and using a multiple-step growth process. The MWCVD deposition protocol is detailed in [8] and summarized in Table 2. Substrates were alternatively biased under $-200 \mathrm{~V}$ (DC). During the deposition time $(6 \mathrm{~h})$, the partial pressure of methane was held at $0.4 \mathrm{hPa}$ [9] and [10]. The temperature of the sample surface measured using an optical Raytek biband pyrometer was set at $1150 \mathrm{~K}$. The protocol has been patented (WO/2010/076423, [11]).

A Philips PW1820 diffractometer was used to determine the crystallographic structure of deposited compounds. Scanning electron microscopy (SEM Jeol JMS 6360A) observations were made to investigate the surface and crosssection morphologies of diamond films. To observe the interfaces and to localize elements, a TEM Jeol 2200FS equipped with a Jeol EDS-STEM system was used. Thin foils were prepared using an EM-09100 JEOL ion slicer system. Raman spectra were collected using a Thermo scientific DXR micro-Raman spectrometer at an excitation wavelength of $633 \mathrm{~nm}$ 
and a laser power of $10 \mathrm{~mW}$. Raman analyses were performed to identify diamond and graphitic phases, to obtain further information on the structure evolution of films and to qualitatively study the residual stresses in the diamond films based on the observation of the peak shifts.

The scratch tests were performed using a Tribotechnic Millenium 100 scratch-tester, in agreement with standard ISO/EN 1071-3. A Rockwell C diamond tip was used as indenter and drawn over the coated surface for $10 \mathrm{~mm}$ length with an applied load increased continuously from 0 up to $50 \mathrm{~N}$.

\section{Results}

Table 3 summarizes the system studied before diamond growth (names, system architecture, layer compositions, thicknesses and TaN grain morphologies and sizes). For TZT system, XRD diffractograms show the presence of both hexagonal (JCPDS 39-1484) and cubic (JCPDS 49-1283) TaN phases, cubic ZrN (JCPDS 35-0753) and cubic Mo (JCPDS 03065-7442) phases. For TNG, same compounds are present but only the TaN cubic phase is detected (Fig. 1). As expected, the use of ion beam leads to a significant reduction of TaN grain size. A structure transition appears from densely fiber grains joined for TaNhex when: (1) layer thickness is reduced as for the multilayered TZT system or (2) grains are rounded shaped (TNG). For TZT, inside the TaN/ZrN multilayer system, columnar growth is stopped thanks to the thickness reduction of the layers (resp. 50 and $30 \mathrm{~nm}$ ) and the formation of new grains when the sputtered phase changed. At the interface between TaN and ZrN layers, the grain boundary continuity is interrupted increasing the grain boundary diffusion path for species inside the multilayer system. The morphology of the grains is columnar for Mo. No porosity was noticed at interfaces or grain boundaries. Although the deposition temperature was $673 \mathrm{~K}$, neither trace of Co inside the diffusion layer nor diffusion of Mo element inside the TaN or ZrN diffusion barriers is observable on EDS-TEM analyses whatever the system studied. The interfaces between TaN and Mo or TaN and ZrN are sharp and clean without any indication of interface reaction. This later result is in agreement with thermochemical calculation from Thermodata Software [12] realized to select bilayer system materials in order to have no reaction at the interface between the nitrides and the molybdenum layer [7].

After diamond deposition at $1150 \mathrm{~K}, \mathrm{XRD}$ patterns (Fig. 1) show the presence of small peaks corresponding to the cobalt phase. On EDS-STEM maps (Fig. 2), no trace of $\mathrm{Co}$ is detected at the diamond interface. Cobalt seems to be confined below the diffusion barrier for TZT and/or at the interface with the nucleation layer for TNG. The figure inserted in Table 4 illustrates the Raman spectra of the as-grown multilayered diamond films deposited on the previous interlayer systems. The most significant feature in these spectra is the weak peak near $1110-1130 \mathrm{~cm}^{-1}$ and the diamond band near $1333 \mathrm{~cm}^{-1}$ (usually identified as the first-order Raman diamond line). The $1110-1130 \mathrm{~cm}^{-1}$ peak has been attributed to either transpara-acetylene [13] or trans-polyacetylene [14] or due to disordered $\mathrm{sp}^{2}$-bonded carbon at the grain boundaries of the NCD film [15], which could be evidence of the presence of NCD as claimed by some authors [16] and validated by TEM observation of the diamond multilayer [8]. The Raman feature near $1570 \mathrm{~cm}^{-1}$ may be related to $\mathrm{sp}^{2}$ bonded carbon (G-band of graphite [17]). No significant modification for the $1333 \mathrm{~cm}^{-1}$ and G-band peak positions is noticed when spectra are compared. However a shift of the 1110-1130 Raman lines is observed from 1113 (for TNG) up to $1133 \mathrm{~cm}^{-1}$ (for TFG). During the CVD process, formation of graphite or diamond requires a sufficiently high carbon concentration at the interlayer surface to promote solid carbon condensation. All our studied systems need one part of carbon species from methane to carburize Mo at the beginning of the process. In addition, the diamond nuclei can also act as localized sources of carbon. According to the phase diagram of Co-C system in the temperature range of 975$1275 \mathrm{~K}$ (typical temperature reached during diamond CVD deposits), carbon solubility is around $0.2-0.3 \mathrm{wt} \%$ in Co, $0.01 \mathrm{wt} \%$ in Mo and comparatively negligible in Ta. The diffusion coefficients of carbon at $1150 \mathrm{~K}$ into TaN, TaC, Mo, $\mathrm{Mo}_{2} \mathrm{C}$ and $\mathrm{ZrN}$ are respectively, $1 \times 10^{-14}, 1 \times 10^{-17}, 1 \times 10^{-4}, 5 \times 10^{-12}$ and $1 \times 10^{-21} \mathrm{~cm}^{2} \mathrm{~s}^{-1}$ [18], [19] and [20]. 


\section{Discussion}

When no additional interlayer system is used, during the initial stage of the CVD process, the WC-Co substrate is directly exposed to a hydrocarbon rich atmosphere and carbon species which diffuse into the bulk of the binder phase until the carbon solubility is exceeded. Once the carbon concentration at the substrate surface is sufficiently large to promote solid carbon condensation, the preferential formation of graphite layer is favored by the presence of the cobalt. Moreover, as a further consequence of carbon high solubility in the cobalt phase, diffusion of carbon from the deposited diamond into the metal binder occurs with a high rate.

When an additional interlayer system is added, as for TNG and TZT, the Mo grains from the top nucleation layer are quickly submitted to a carburization process at the initial stage of CVD process and transformed into carbide phase like $\mathrm{Mo}_{2} \mathrm{C}$ (JCPDS 03-65-8766) and MoC (JCPDS 03-65-3494) as confirmed by XRD ( Fig. 1) and TEM diffraction analyses. Simulation of the carburization reactions is done based on the following equation using thermodata software :

equation(1)

$\mathrm{MN}(\mathrm{s})+\mathrm{CH}_{4}(\mathrm{~g}) \rightarrow \mathrm{MC}(\mathrm{s})+2 \mathrm{H}_{2}(\mathrm{~g})+1 / 2 \mathrm{~N}_{2}(\mathrm{~g})$ with $\mathrm{M}=\mathrm{Ta}$ or $\mathrm{Zr}$

equation(2)

$x \mathrm{M}(\mathrm{s})+y \mathrm{CH}_{4}(\mathrm{~g}) \rightarrow \mathrm{M}_{x} \mathrm{C}_{y}(\mathrm{~s})+2 y \mathrm{H}_{2}(\mathrm{~g})$ with $\mathrm{M}=\mathrm{Mo}, y=1$ and $x=1$ or 2

The same calculations were performed with $\mathrm{CH}_{3}, \mathrm{CH}_{2}$ and $\mathrm{C}_{2} \mathrm{H}_{2}$ leading to the same conclusions. When the permanent rate (considered as thermodynamical equilibrium) inside the closed CVD reactor is reached, $100 \%$ of the Mo and $90 \%$ of TaN are carburized in temperature range of 1050-1170 K (1150 K for our CVD condition). Carburization of ZrN might also be started but lower than $1 \%$ of $\mathrm{ZrN}$ is supposed to be transformed at a temperature up to $1200 \mathrm{~K}$. Consequently, ZrN is still stable during CVD process. It has been also confirmed during the study of a bilayer ZrN/Mo system [7] and for the TZT system. TEM observations and XRD results validate that an entire TaN carburization (TaC JCPDS 65-8264) occurs during process whatever the system tested (TFG, TNG or TZT). So when Mo layer is continuous and because the TaN layer is also carburized during the process, the bilayer system composed of TaN/Mo could rather be considered as a regulator for the diffusion of carbon. This feature could lead to the control of the formation of graphite at the top surface during the beginning of the CVD process.

In a previous study [7], we have decorrelated the beneficial effect of Mo layer on diamond nucleation from the bias one during the diamond film deposition. The etching effect of the bias under $\mathrm{H}_{2}$ rich atmosphere, allows growing NCD diamond whereas the Mo thin layer improves the formation of $\mathrm{sp}^{3}$ species. The presence of a continuous Mo interlayer carburized in direct contact with the outermost diamond film during the CVD process, could provide a stronger chemical bonding if it helps to reduce graphite content at this interface. In order to bring information about the system efficiency to prevent the graphite formation, HRTEM observations have been performed. For the TFG system when Mo layer continuity is interrupted, a quasi-continuous layer of graphite with an average thickness of $100 \mathrm{~nm}$ is observed (Fig. 3).

In the case of a direct exposition of the TaN or ZrN diffusion layer to the carbon species, carbon diffusion phenomenon are then controlled by the carbon diffusion properties in TaN/TaC or ZrN. The Louchev et al. [21] model developed to understand carburization, considers: the adsorption/desorption of carbon species, thermal dehydrogenation of carbon, carbon evaporation, insertion of carbon atoms into the solid from the surface and bulk diffusion. They have supposed the carburization is carbon bulk diffusion limited. This is the slowest phenomenon but significantly faster than the kinetic of carburized species formation. Because $\mathrm{CH}_{4}$ is unable to be chemisorbed, only $\mathrm{C}_{2} \mathrm{H}_{2}$ is considered. They show that the carbon surface concentration depends on the equilibrium between the flow of carbon species absorbed and desorbed. The authors suggested an increase of carbon sursaturation due to the increase of adsorption energy of the surface after its carburization. This point of view even ignores the contribution of the diamond nucleus or grains present 
at the surface. However, it allows explaining a preferential nucleation of diamond on tips of surface protrusions, the increase of the induction time of nucleation for materials with higher diffusion coefficients, the thickness decrease of the carbonized layer when increasing the methane fraction in the feed gas and the possibility of nucleation without the preliminary stage of carbonization.

Difference of the carbon diffusion coefficient (four decades) could help to justify why a bimodal distribution of nanosized diamond clusters is observed with $\mathrm{ZrN} / \mathrm{Mo}$ and a homogeneous distribution with TaN/Mo [8]. Some authors [22] also consider that for intermediate diffusion coefficients, rapid carbon surface saturation occurs. First nuclei are formed then grow leading to the formation of a continuous diamond layer with homogeneous grain size. Anyone integrates additional effect due to the use of a negative bias during the sequenced diamond deposit, with the consequences of new nucleus site formation (benefic for the formation of a continuous layer [8]) and dissolution of graphite and diamond nuclei (acting as localized additional carbon sources). Consequences are direct on the quantity of carbon species present at the surface during the formation of the diamond. Due to the difference of carbon diffusion coefficient values (lowest for ZrN), a partial dissolution of first nuclei (less numerous and bigger for ZrN/Mo than for TaN/Mo system) occurs following with a secondary nucleation directly on these nuclei leading to the growth of the cluster whereas new nuclei are formed on the surface.

The diamond nucleation mechanism modifications occurring due to nitrogen diffusion under $\mathrm{H}_{2} / \mathrm{CH}_{4}$ flow, to the best of our knowledge, are not treated in the literature. Carbon concentration at the surface results from the exchanges between the carbon species "oncoming" (from the gaz phase) and those "outgoing" consequence of carbon diffusion inside the bulk system and also carbon desorbed by evaporation. Presence of nitrogen species should modify the thermochemical and kinetic conditions at this interface. Based on the Louchev approach [21], we propose to list in Fig. 4, the supposed phenomenon occurring at TaN layer surface during CVD diamond deposit process with $\mathrm{CH}_{4} / \mathrm{H}_{2}$ working atmosphere. Carburization of TaN is added with consequence of nitrogen diffusion into the bulk and/or nitrogen desorption at the top interface. Chemical potentials are then locally modified with the consequence of an increase of the carbon species on the surface. This phenomenon could be pronounced with the use of the bias and the presence of carburized species at surface [21]. As a consequence, graphite layer formed at the interface is most important when nitride carburization occurs: one hundred of nanometers with TaN/Mo ( Fig. 3) reduced to about five with ZrN/Mo (not presented).

When nucleation layer continuity is preserved, at the beginning of the process as for the TNG and TZT systems, small grains of diamond are directly formed at the top surface exhibiting a discontinuous diamond layer in direct contact with the $\mathrm{Mo}_{2} \mathrm{C}$ (or $\mathrm{MoC}$ ) layer. These areas are surrounded by a very thin graphite layer with an average reduced thickness of $10 \mathrm{~nm}$ ( Fig. 3) also in direct contact with the $\mathrm{Mo}_{2} \mathrm{C}$ layer. Nucleation of diamond is controlled by exchanges occurring at the surface of this nucleation layer. Control of species present at the surface is then based on carbon diffusion coefficient value for molybdenum and the molybdenum carbides. However, TaN carburization still occurs independently of the studied system. The presence of a continuous Mo layer, its carburization and its well-known affinity for Co (solid solution and binary compounds formation [7]) as well as the carburization of the compounds formed may change the system close to the interface with diamond. The Mo carburized layer combined with the effect of a substrate bias etching, is supposed to increase the concentration of carbon reactive species close to the top surface. But progressive chemical transformation of the nitride into carbide still occurs and requires the use of carbon. Independently of the interlayer system architecture when a top bilayer TaN/Mo system is used, we have noticed that the formed graphite layer thickness is reduced down to few $10 \mathrm{~nm}$. In this case, the carburization of the nitride acts as a regulator phenomenon for the control of carbon species at the top interface and helps to reduce the quantity of graphite formed and the quantity of diamond nuclei dissolved. This control of the carbon species sursaturation at the surface helps also to understand why diamond cluster dimension is modified when the number of nucleus increases ( Fig. 5). This has also to be correlated with efficiency of the cobalt diffusion barrier. For NCD peak in Raman spectra, a shift from 1113 for TNG and 1120 for TZT up to $1133 \mathrm{~cm}^{-1}$ for TFG is noticed. When diamond grain sizes are higher than $20 \mathrm{~nm}$, this shift 
might be related to residual stresses in the film. But our NCD diamond multiple-step growth process leads to diamond grain sizes around $1.1 \pm 0.3 \mathrm{~nm}$ for the biased and $9.0 \pm 4.0 \mathrm{~nm}$ for the unbiased sequences [8]. In our case, because under layer system architecture is changed whereas the NCD diamond layer morphology is unaltered, this shift might be attributed to the existence of residual stresses at the interface with the interlayer system. Sun [23] reported that the possible origin of such a shift could be a compressive stresses effect. In this case, this shift should indicate an increase of the compressive stress for TFG with respect to TZT and TNG. It has to be correlated with the presence of an additional layer over the Mo nucleation layer: the continuous graphite layer. This "new layer" leads to a change of the distribution of stress values in the real system thanks to its specific mechanical properties due to its $2 \mathrm{D}$ particular layered structure.

However depending on the architecture of the interlayer, the Co diffusion is modified. Presence of the Mo continuous layer leads to confine Co closed to the interface with the substrate for TZT system or closed to the interface between Mo and TaN layers for TNG (Fig. 2). Average grain boundary length necessary to species for crossing the layer from the interface with the substrate to the interface with Mo, is comparable for TNG and TFG. Density and linearity of grain boundaries as TaN crystallography changes (phase and texture), could explain the modification of species behaviors without taking into account the volume diffusion. There is an anisotropy of diffusion phenomenon due to texture as already observed by Czerwiec et al. [24] for AIN and by He et al. [25] during plasma assisted nitriding of a Ni-based alloys.

When a multilayer architecture is used, change of chemical environment due to the presence of $\mathrm{ZrN}$, also modifies the diffusion phenomenon. There is an increase of diffusion path lengths due to non-connecting grain structures between contacted phases (e.g. case of TZT system; Table 1). Additionally, stresses generated inside the different layers depend on the process step (after or before diamond growth) and interlayer architecture. Thermomechanical simulation results show that diamond layer is in tension and that the stress values reached depend on the interlayer system [8]. But in this case, the properties variations due to microstructural changes such as grain size and texture are not taken into account. However the stresses generated inside the surrounding layers ( $\mathrm{rNN}$ or Mo) are different if the TaN layer thickness is modified. But stress state of the layer and of the grains has also an effect on the diffusion phenomenon as their velocity [24] and [25]. Combined with the microstructural changes (phase, grain size, etc.), this can justify the best efficiency of the multilayer (ZrN/TaN system) as Co diffusion barrier. This also can impact the carbon diffusion phenomena during CVD process especially for bilayer systems.

In this study, electromigration of species can also occur during the CVD process due to the sequenced applied bias. Diffusion can be influenced by this applied electric field. In a previous study, Manaud et al. [6] have shown that without using bias and a TaN diffusion barrier is the best system to prevent cobalt diffusion. Using bias, Poulon et al. [7] have reported that ZrN is the best barrier to prevent cobalt diffusion. The used of bias is necessary to obtained NCD and possibly modifies the diffusion behavior of cobalt. But diffusion phenomena are very complex and complementary investigations are necessary to well understand the electromigration contribution that is not yet reported.

The adhesion of coatings evaluated by scratch-testing show that continuous peeling occurs at a critical load of about 15, 19 and $25 \mathrm{~N}$ for TNG, TFG and TZT systems, respectively. For TZT, continuous peeling directly occurs whereas for TFG and TNG first ships start to appear at 2 and $10 \mathrm{~N}$. These results reveal that the control of graphite presence at the interface with the NCD layer is a necessary but not sufficient condition. Control of residual stresses has also to be taken into account. The time-modulated polarization process during MWCVD diamond deposition combined with a controlled architecture of the interlayer system helps to improve adhesion of NCD layer by both the control of the stress distribution and the graphite formation at the interface with the diamond layer. Compared to TFG system, gains are substantial for TZT (+31.5\%) not for TNG (-21\%). TZT system seems to be promising for improving the adhesion of NCD layer. 


\section{Conclusions}

In this study, correlation between the architecture of the systems and the diffusion phenomenon occurring during the CVD diamond deposit has been established to understand which parameters of the architecture allow to control the graphite formation at the interface with diamond top layer. Two new type of architectures for the diffusion layer have been studied: (1) TNG: single TaN layer and an additional Mo nucleation layer and (2) TZT: a multilayer system composed of nine periods of a TaN/ZrN bilayer under a TaN diffusion barrier layer and a Mo nucleation layer. After diamond deposit, these two systems show an interface with the diamond layer free of cobalt so assumed to be more adhesive thanks to the reduction of the $\mathrm{sp}^{2}$ graphitic species quantity. The possibility of TaN and Mo in situ carburization during the CVD process combined with the optimized process parameters, allows a significant reduction of the graphite at the interface with the diamond layer. The use of a multilayer system composed of one part dedicated to the nucleation improvement and the other separated from the previous, dedicated to the control of cobalt diffusion from the substrate, seems to be an innovative solution to control the diffusion phenomenon of both carbon and cobalt (confined close to the interface with the WC-Co substrate). The nucleus density is increased while decreasing the amount of graphite at the interface with the continuous diamond layer.

However the control of graphite presence at the interface with the NCD layer is a necessary but not sufficient condition to significantly improve the NCD layer adhesion. Residual stresses play also a key role. The time-modulated polarization process during MW-CVD diamond deposition combined with a controlled architecture of the interlayer system helps to increase the critical load reach for the continuous peeling of the NCD layer. Based on this study, the TZT system seems to be promising for improving the performance of NCD coated cutting. 


\section{References}

[1] C. Artini, M.L. Muolo, A. Passerone, J. Mater. Sci. 47 (2012) 3252-3264.

[2] K. Mallika, R. Komanduri, Wear 224 (1999) 245-266.

[3] J.B. Donnet, D. Paulmier, H. Oulanti, T. Le Huu, Carbon 42 (2004) 2215-2221.

[4] S. Amirhaghi, H.S. Reehal, R.J.K. Wood, D.W. Wheeler, Surf. Coat. Technol. 135 (2001) 126-138.

[5] R. Polini, Thin Solid Films 515 (2006) 4-13.

[6] J.P. Manaud, A. Poulon, S. Gomez, Y. Le Petitcorps, Surf. Coat. Technol. 202(2007) 222-231.

[7] A. Poulon-Quintin, C. Faure, L. Teulè-Gay, J.P. Manaud, Thin Solid Films 519 (2010) 1600-1605.

[8] C. Faure, L. Teulè-Gay, J.P. Manaud, A. Poulon-Quintin, Surf. Coat. Technol. 222 (2013) 97-103.

[9] C.L. Geng, WZ. Tang, L.F. Hei, S.T. Liu, F.X. Lu, Int. J. Refract. Met. Hard Mater. 25 (2007) 159-165.

[10] M.A. Neto, E. Pereira, Diam. Relat. Mater. 15 (2006) 465-471.

[11] J.P. Manaud, A. Poulon-Quintin, L. Teule-Gay, C. Faure, International Patent WO/2010/076423.

[12] B. Cheynet, P.Y. Chevalier, E. Fischer, Thermosuite Calphad 26 (2) (2002) 167-174.

[13] A.C. Ferrari, J. Robertson, Phys. Rev. B 63 (2001) 1214051-1214054.

[14] H. Kuzmany, R. Pfeiffer, N. Salk, B. Gunther, Carbon 42 (2004) 911-917.

[15] J. Birrell, J.E. Gerbi, O. Auciello, J.M. Gibson, J. Johnson, J.A. Carlisle, Diam. Relat. Mater. 14 (2005) 86-92.

[16] Z. Sun, J.R. Shi, B.K. Tay, S.P. Lau, Diam. Relat. Mater. 9 (2000) 1979-1983.

[17] R. Pfeiffer, H. Kuzmany, P. Knoll, S. Bokova, N. Salk, B. Gunther, Diam. Relat. Mater. 12 (2003) 268-271.

[18] R. Resnick, L. Seigle, Trans. Metall. Soc. AIME 236 (1966) 1732-1738.

[19] Y.F. Khromov, V.P. Yanchur, V.S. Eremeev, Fiz Metal. Metalloved 33 (1972) 642-644.

[20] A.V. Shovensin, G.V. Scherbedinskii, A.N. Minkevich, Poroshk. Metall. 11 (1966) 46-55.

[21] O.A. Louchev, C. Dussarat, Y. Sato, J. Appl. Phys. 86 (1999) 1736-1743.

[22] P.O. Joffreau, R. Bichler, R. Haubner, B. Lux, Int. J. Refract. Met. Hard Mater. 7 (1988) 92-97.

[23] F.H. Sun, Z.M.Zhang, M. Chen, H.S. Shen, Diam. Relat. Mater. 12 (2003) 711-718.

[24] T. Czerwiec, N. Renevier, H. Michel, Surf. Coat. Technol. 131 (1-3) (2000) 267-277.

[25] H. He, J. Zou, C. Dong, T. Czerwiec, H. Michel, Mater. Sci. Forum 475-479 (2005) 3669-3672. 
Table 1

Reactive sputtering deposition parameters used with substrate temperature fixed at $673 \mathrm{~K}$.

\begin{tabular}{|c|c|c|c|c|c|c|}
\hline Sample & Total pressure $(\mathrm{Pa})$ & Partial $\mathrm{N}_{2}$ pressure $(\mathrm{Pa})$ & $\mathrm{N}_{2}$ percentage (\%) & Power density $\left(\mathrm{W} \mathrm{cm}^{-2}\right)$ & Target voltage (V) & Deposition rate $\left(\mathrm{nm} \mathrm{min}^{-1}\right)$ \\
\hline $\mathrm{TaN}$ & 0.5 & 0.05 & 10 & 2.3 & -160 & 10.0 \\
\hline $\mathrm{ZrN}$ & 0.5 & 0.03 & 6 & 4.0 & -280 & 16.5 \\
\hline Mo & 0.5 & - & - & 2.3 & -190 & 20.0 \\
\hline
\end{tabular}

Table 2

Bias sequenced MWCVD deposition parameters of diamond film at $1150 \mathrm{~K}$.

\begin{tabular}{|c|c|c|c|c|c|c|c|}
\hline & Sequence & $\mathrm{CH}_{4}(\%)$ & $\begin{array}{l}\text { Total flow rate } \\
\left(\mathrm{cm}^{3} / \mathrm{min}\right)\end{array}$ & Pressure (hPa) & $\begin{array}{l}\text { Negative bias } \\
\text { (V) }\end{array}$ & $\begin{array}{l}\text { Sequence } \\
\text { duration (h) }\end{array}$ & $\begin{array}{l}\text { Total step } \\
\text { duration }(\mathrm{h})\end{array}$ \\
\hline First nucleation step & Biased & 3.0 & 230 & 40 & -200 & 0.5 & 0.5 \\
\hline \multirow[t]{2}{*}{ Polarized modulation growth step } & Unbiased & 0.8 & 440 & 40 & 0 & 0.5 & $6 h 30$ \\
\hline & Biased & 0.8 & 440 & 40 & -200 & 0.5 & \\
\hline
\end{tabular}

Table 3

Coating architecture presentation: TaN nano-grained bilayer system (TNG) and TaN-ZrN multilayer coated with a TaN/Mo bilayer system (TZT).

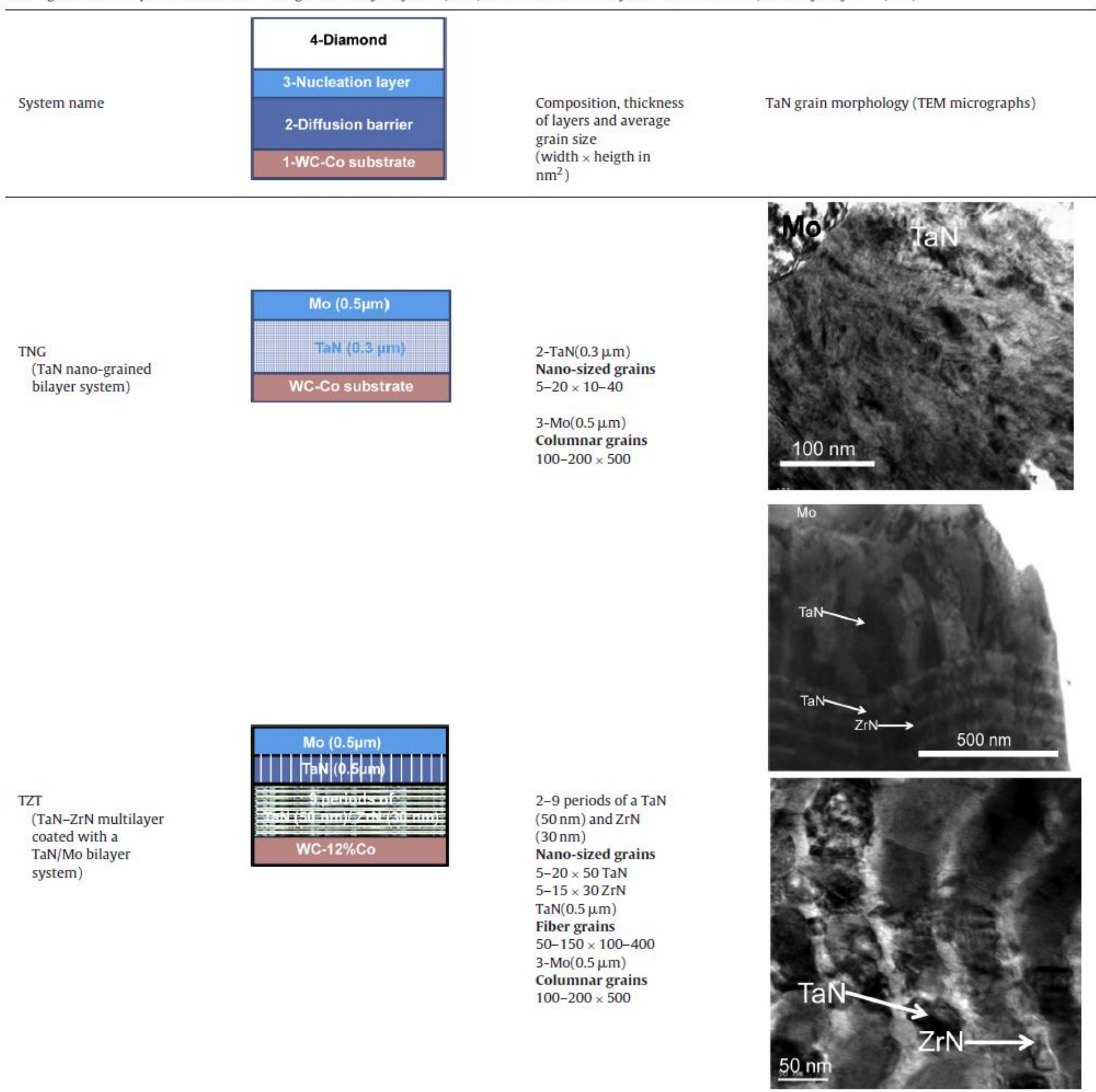


a)

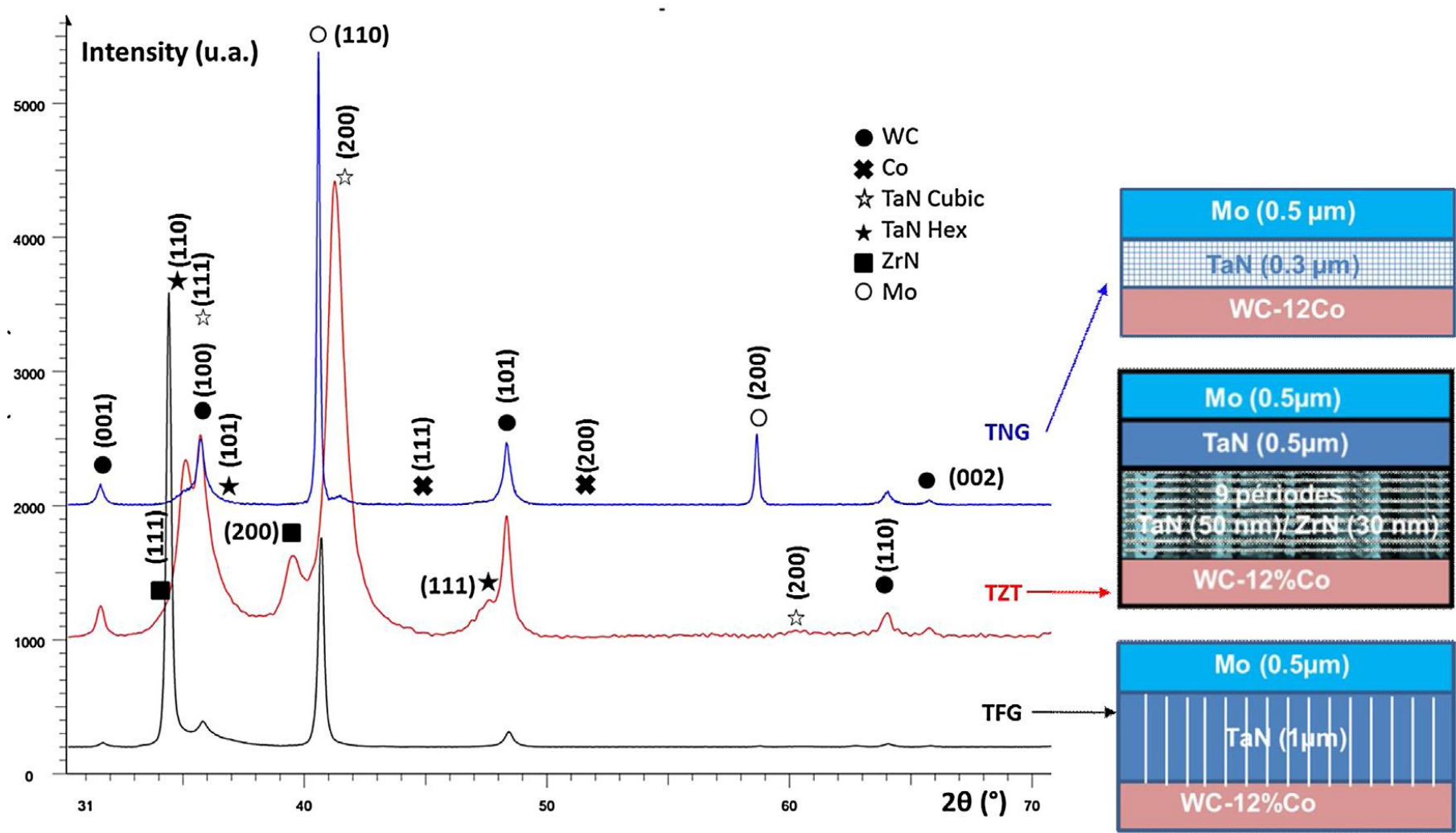

b)

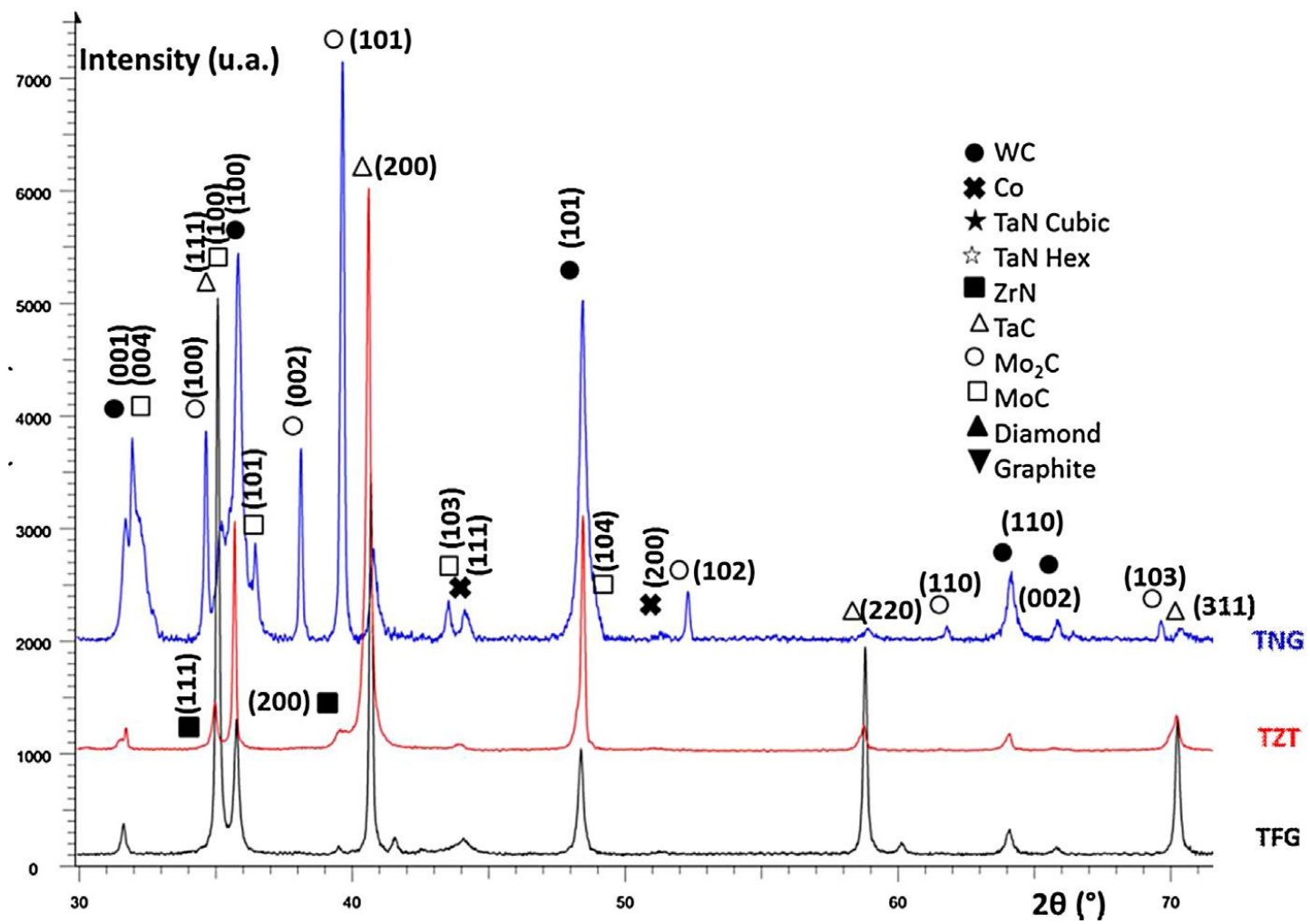

Fig. 1. X-ray diffraction patterns of TFG (TaN/Mo bilayer system with TaN columnar grains), TZT (TaN-ZrN multilayer coated with a TaN/Mo bilayer system) and TNG (TaNnano-grained bilayer system) systems deposited onto WC-Co substrates (a) before and (b) after diamond growth. 


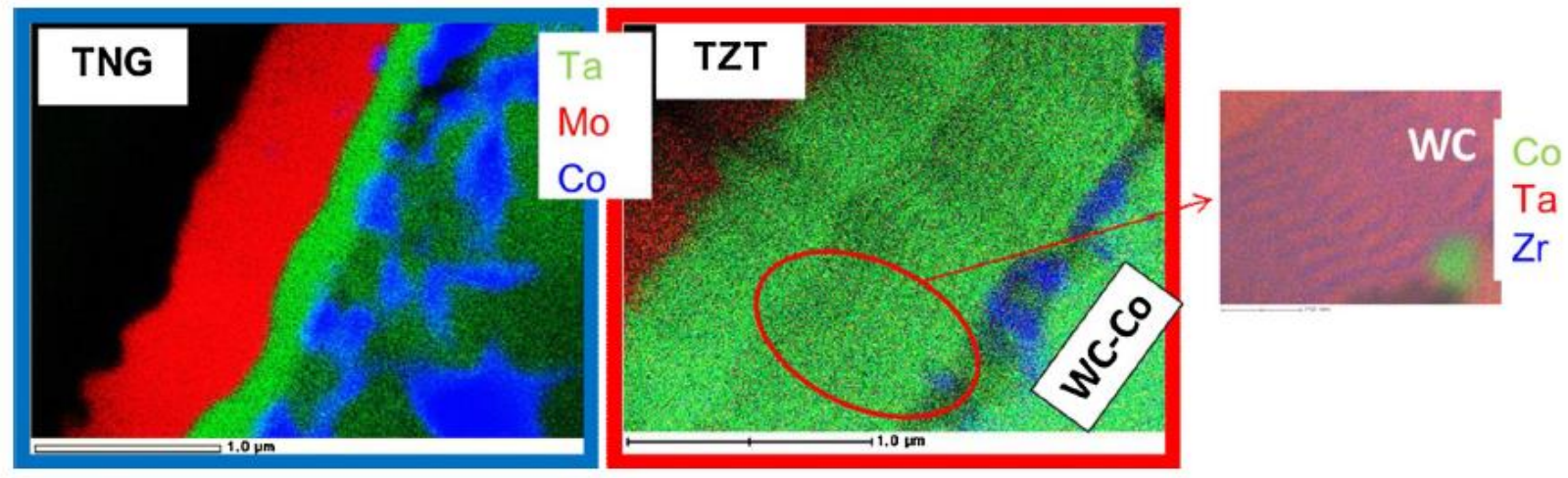

Fig. 2. Overlay EDS-STEM images of Ta, Zr, Mo and Co for the (TaN/Mo bilayer system with TaN columnar grains), TZT (TaN-ZrN multilayer coated with a TaN/Mo bilayer system) and TNG (TaN nano-grained bilayer system) systems after diamond growth.
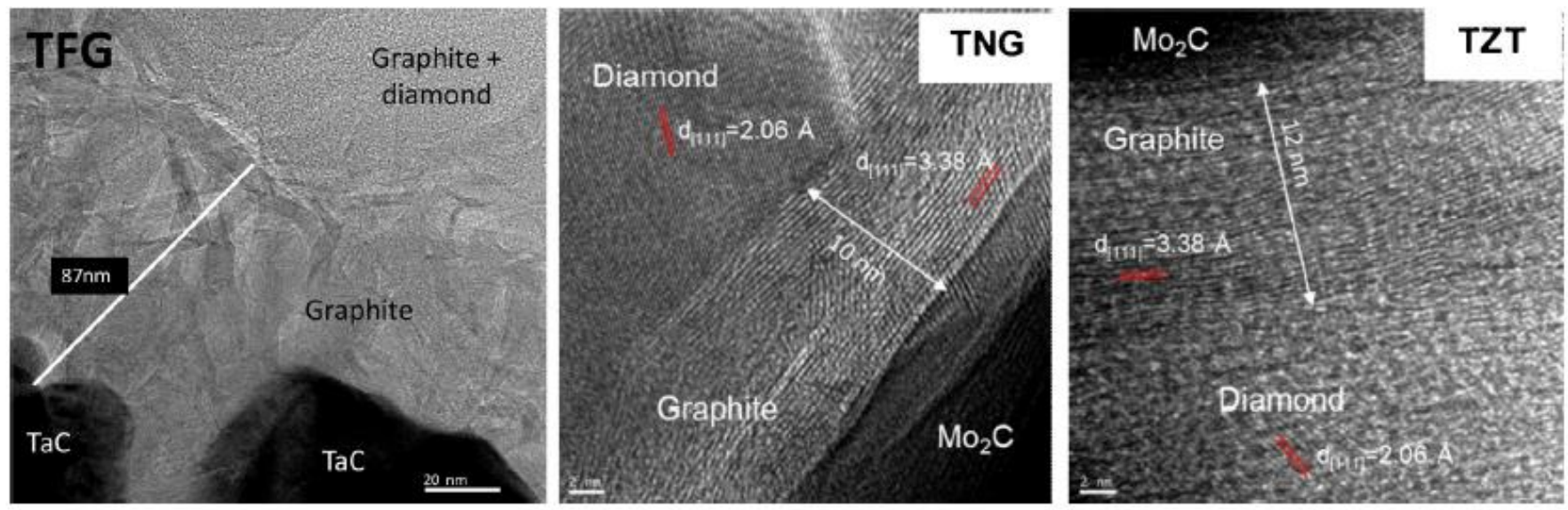

Fig. 3. HRTEM pictures of the interfaces of the diamond layer with the Mo carburized layer for the TFG, TNG and TZT systems.

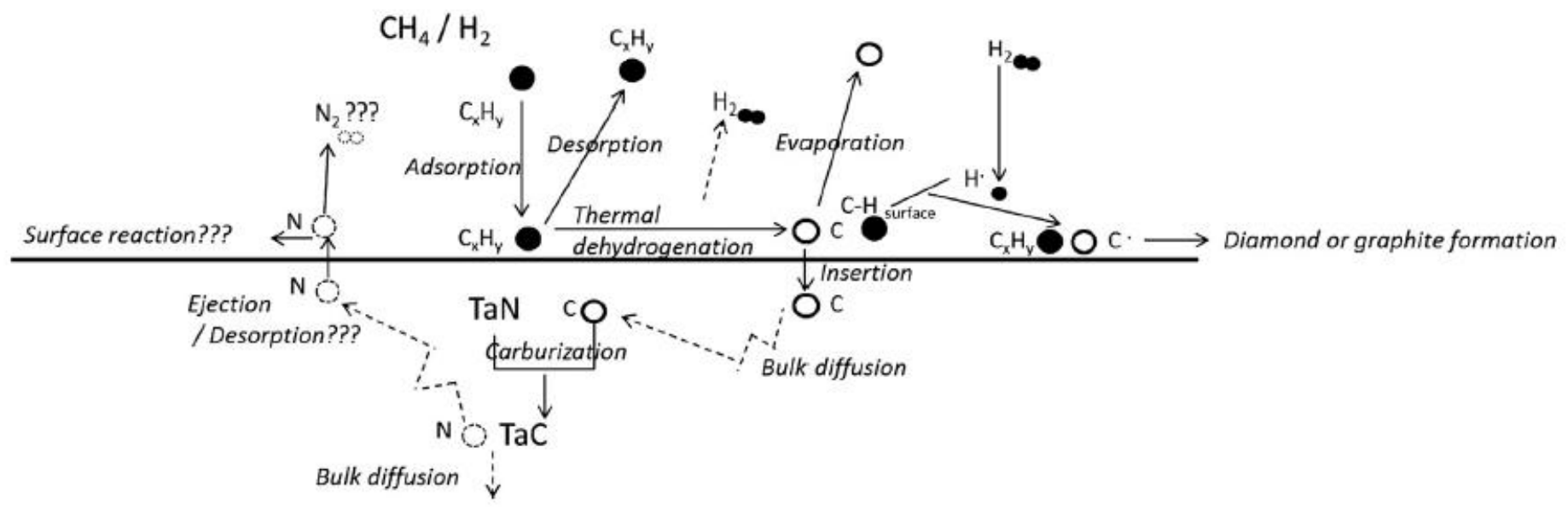

Fig. 4. Schematic representation of phenomenon occurring at surface of a TaN diffusion layer during the beginning of the diamond deposit. 

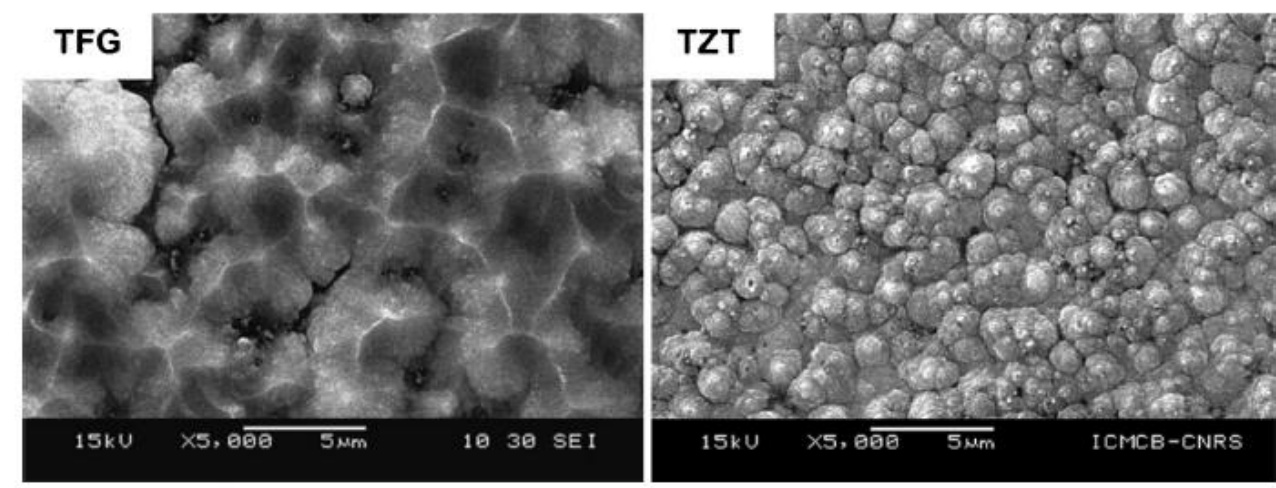

Fig. 5. SEM microsgraphs of the diamond layer surface when a TaN/Mo bilayer system is used and the molybdenum nucleation layer interrupted (TFG) or continuous (TZT).

Table 4

Raman spectra of the NCD films deposited on the TFG (TaN/Mo bilayer system with TaN columnar grains), TZT (TaN-ZrN multilayer coated with a TaN/Mo bilayer system) and TNG (TaN nano-grained bilayer system) interlayer systems and Raman peak position (NCD and diamond). SEM cross-section view of the diamond layer [8].

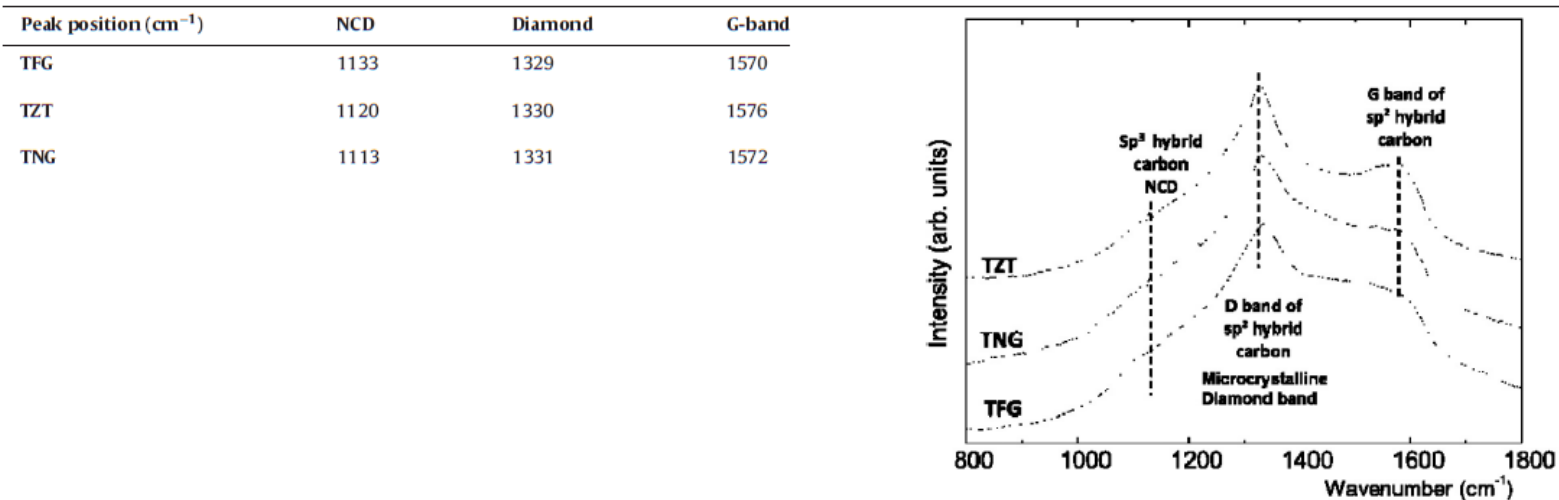

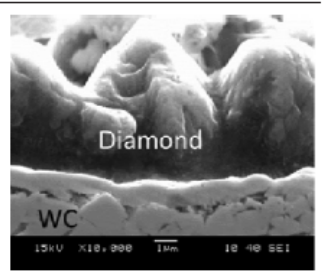

